\title{
MODELAGEM E EDUCAÇÃO PROFISSIONAL: POSSÍVEIS RELAÇÕES EM UMA ABORDAGEM PEDAGÓGICA PARA SOLUÇÕES QUÍMICAS NO ENSINO MÉDIO INTEGRADO AO TÉCNICO EM INFORMÁTICA
}

\author{
L. P. GANDRA* , A. G. V. FARIA e G. S. SANTOS \\ Instituto Federal de Educação, Ciência e Tecnologia do Rio Grande do Norte \\ luca.gandra@hotmail.com*
}

Artigo submetido em outubro/2013 e aceito em dezembro/2013

DOI: $10.15628 /$ rbept.2013.3453

\section{RESUMO}

O presente artigo procura apresentar os resultados de uma pesquisa qualitativa, que analisa o desenvolvimento de atividades integradoras fundamentadas em modelagem como estratégia didática para o ensino médio integrado ao técnico em informática. Objetiva-se, por meio das ações da pesquisa, realizar atividades que contribuam para a formação geral e específica dos discentes bem como para o enriquecimento pedagógico dos docentes que por ventura venham a se utilizar dessas atividades. $\mathrm{O}$ trabalho analisou os modelos produzidos ao longo das atividades de modelagem, trazendo resultados que podem subsidiar discussões a fim de fortalecer as concepções pedagógicas que permeiam o ensino médio integrado à educação profissional.

PALAVRAS-CHAVE: Modelagem, integração, Educação Profissional.

\section{MODELING AND VOCATIONAL EDUCATION: POSSIBLE RELATIONS IN AN PEDAGOGICAL APPROACH TO CHEMICAL SOLUTIONS IN HIGH SCHOOL INTEGRATED INTO THE TECHNICAL EDUCATION IN COMPUTER SICENTE}

\begin{abstract}
This article presents the results of a qualitative research, which analyzes the development of integrated activities based on modeling as a teaching strategy for high school integrated into the technical education in computer science. The objective is, through research actions, perform activities that contribute to the general and specific training of students as well as for the pedagogical
\end{abstract}

enrichment of teachers that perhaps should come to use these activities. The study analyzed the models produced along the modeling activities, bringing results that can support discussions to strengthen the pedagogical concepts that permeate the high school integrated to vocational education.

KEYWORDS: Modeling, integration, vocational education. 


\section{INTRODUÇÃO}

A rede federal de Educação Profissional, Científica e Tecnológica (EPCT) teve início em 1909, sob a iniciativa do então presidente da Republica Nilo Peçanha quando criou as escolas de Aprendizes e Artífices, que mais tarde, deram origem aos Centros Federais de Educação Tecnológica-CEFETS (BRASIL, 2007).

Com a publicação da lei 11.892 de 29/12/2008 são criados os Institutos Federais, a partir da transformação de CEFETS, que juntamente com as escolas agrotécnicas federais, Colégio Pedro II do Rio de Janeiro e escolas técnicas vinculadas a universidades vem constituir a de Rede Federal de EPCT, que hoje conta com 562 unidades em funcionamento por todo o território nacional ${ }^{1}$.

Com a expansão da Rede Federal de EPCT, que em 2002 contava com 140 unidades e passa a ter 562 em 2015, temos como consequência uma grande ampliação da oferta de vagas para alunos em várias modalidades de ensino, na qual dentre elas, para esse artigo, atribuímos destaque para o ensino médio integrado à educação profissional. Pensando sob essa perspectiva, nossa pesquisa descrita nesse artigo pretende investigar se é possível desenvolver atividades integradoras para o ensino médio integrado ao técnico em informática fundamentadas na modelagem como estratégia didática?

\section{REVISÃO BIBLIOGRÁFICA}

\subsection{Práticas Integradoras em Educação Profissional}

No levantamento bibliográfico no sítio da SETEC, acerca do ensino médio integrado à EPCT, Gandra e Figueiredo (2013) apontam que dentre os textos disponíveis que remetem a esta temática, o principal é o documento base intitulado "Educação Profissional Técnica de Nível Médio Integrada ao Ensino Médio". Essa produção, disponibilizada em 2007, aponta que de acordo com o PDE (Plano de Desenvolvimento da Educação), a modalidade de ensino integrado é a que apresenta melhores resultados pedagógicos, remetendo tais conquistas ao que é observado na LDB quando trata "Da educação profissional técnica de nível médio" e pelo decreto n 6.302 , de 12 de dezembro de 2007 que estabelece o Programa Brasil Profissionalizado.

Ramos (2005) relata que esta modalidade de ensino é viável, pois, “o ensino médio integrado ao ensino técnico, sob uma base unitária de formação geral, é uma condição necessária para se fazer a travessia para uma nova realidade".

Tratando-se da formação do discente no ensino médio integrado a educação profissional, é importante destacar essa modalidade não pode ser vista de forma simplista e reducionista, como um ensino que visa à mera preparação para o aspecto operacional do trabalho, escoimado dos conhecimentos que estão em sua gênese científico-tecnológica bem como na sua apropriação histórico-social (CIAVATTA, 2005). Ainda segundo a autora esta modalidade de ensino tem como preocupação a formação humana, buscando o direito a uma formação completa do trabalhador, que vai desde a compreensão de mundo, até atuação como cidadão pertencente a uma nação, e integrado dignamente ao seu contexto político.

${ }^{1}$ Disponível em: http://redefederal.mec.gov.br/ Acesso em: 12-05-2015. 
Do ponto de vista pedagógico o documento base do ensino integrado traz alguns princípios e concepções que objetivam a formação completa como discutido anteriormente. Para o documento:

\footnotetext{
"Em se tratando da formação profissional no ensino médio, queremos dizer que os conhecimentos específicos de uma área profissional não são suficientes para proporcionar a compreensão global da realidade. Por isso, deve-se contemplar também a formação geral. Porém, tanto se pode ir aprendendo conceitos específicos a partir dos conceitos gerais quanto o contrário" (BRASIL, P. 51, 2007).
}

Com essas reflexões, percebemos a necessidade de estabelecer relações entre os conhecimentos específicos de cada área profissional com os conhecimentos gerais das disciplinas como física, química, matemática, geografia e etc. Para o estabelecimento dessas relações recorremos a ideia de integração proposta para a EPCT, que para Ramos (2008) possui três significados que se complementam o $1^{\circ}$ da formação omnilateral, o $2^{\circ}$ da indissociabilidade entre Educação Profissional e Educação Básica e o $3^{\circ}$ da integração de conhecimentos gerais e específicos em uma perspectiva de totalidade.

Destacamos neste trabalho o 3ㅇsignificado, na qual a integração de conhecimentos para à EPCT vem superar a divisão comum do currículo da EPCT em núcleo comum que constitui-se de disciplinas da formação geral como química, arte, geografia, filosofia, etc, e o núcleo específico, composto por disciplinas específicas que demanda cada área profissional (RAMOS, 2008).

Em outras palavras trata-se de integrar os conhecimentos até então fragmentados de ambos os núcleos em uma perspectiva de totalidade, ao qual a interdisciplinaridade torna-se essencial, atuando como princípio organizador do currículo, e ainda como método de ensinoaprendizagem, uma vez que a resolução de problemas requer muitas vezes de conceitos de diversas disciplinas (BRASIL, 2007).

Visando a tal integração de conhecimentos, Araújo (2013) discute vários aspectos políticopedagógicos de práticas integradoras, ao qual o autor considera a possibilidade de existência de práticas pedagógicas que mais se adequam ao projeto de ensino integrado, mas também, recusa a ilusão de existir apenas uma maneira de propiciar a integração parte-todo, afinal há uma vasta gama de procedimentos que, em função da matéria, dos alunos e das finalidades educacionais específicas, podem favorecer mais ou menos para a formação completa que concebe a proposição de um projeto de ensino integrado.

Negamos aqui o entendimento de integração como sinônimo de interdisciplinaridade, pois consideramos a prática integradora uma atividade que ultrapassa a interdisciplinaridade abrangendo além das questões multidisciplinares aspectos pragmáticos aplicado a resolução de problemas previstos dentro de cada área profissional. Além de todos esses aspectos, essa modalidade de ensino deve considerar também a historicidade do estudante permitindo que o seu cotidiano seja evidenciado. Uma vez que a apropriação e a internalização dos problemas podem servir como motivadores pedagógicos.

Enfim, ancorados nesses princípios já disseminados na literatura e por concepções aqui assumidas sobre o ensino médio integrado a educação profissional, é que nos propomos em desenvolver atividades integradoras para o curso de ensino médio integrado ao técnico em informática no campus Coxim do IFMS. 


\subsection{Modelagem}

O processo de atividades que envolvem a construção, adaptação e testes de modelos no ensino de ciência é proposto inicialmente por John Clement (1989), ao qual recebe valiosas contribuições de Justi e Gilbert (2002), e que ficou conhecido no Brasil como Modelagem (FERREIRA, e JUSTI, 2008), que entendemos como uma estratégia didática para o ensino de ciências que se fundamenta em atividades investigativas objetivando a construção, adaptação e teste de modelos.

O uso de modelos é bastante frequente dentro e fora da educação, com várias possibilidades e representações. Sendo assim, entende-se aqui por modelo como:

\footnotetext{
"Uma representação parcial de um objeto, evento, processo ou ideia que é produzida com propósitos específicos como, por exemplo, facilitar a visualização, fundamentar a elaboração e teste de novas ideias, possibilitar a elaboração de explicações e previsões sobre comportamentos e propriedades do sistema modelado" (GILBERT, BOULTER E ELMER, 2000).
}

Para Nersessian (1998) na ciência existem os modelos mentais que se tratam de representações e construções pessoais elaboradas na mente, compactuando com a ideia, de que estes modelos são intrínsecos à cognição humana. Conforme esses modelos mentais passam do cognitivo pessoal para uma entidade acessível a todos agentes externos, tornam-se modelos expressos (GILBERT, BOULTER E ELMER, 2000). Para Mendonça (2008), quando estes modelos expressos atingem um estado de aceitação e reconhecimento social, por meio de testes e são aprovados por uma comunidade científica, passam a ser denominados modelos científicos, uma vez que estes modelos algumas vezes são complexos e abstratos, é uma prática comum dos docentes utilizarem em sala de aula versões simplificadas que são os chamados modelos curriculares. E por fim, ainda quando necessário, para auxiliar os discentes na compreensão em aspectos dos modelos curriculares, os docentes utilizam modelos de ensino ou didático que são representações bi ou tridimensionais, analogias ou ainda simulações computacionais (GILBERT, BOULTER E ELMER, 2000).

No que tange a modelagem como estratégia didática, Clement (2000), traz que esse processo permite ao estudante visualizar conceitos abstratos, por meio de representações parciais, tornando os conceitos mais acessíveis aos discentes. E ainda, propicia aos envolvidos o conhecimento do ambiente da ciência, bem como a compreensão de como se dá a construção do conhecimento científico, aja vista a importância dos modelos para a ciência. E isso a nosso ver, pode contribuir para a formação crítica e abrangente do discente como cidadão.

Estudos apontam que a modelagem pode contribuir para a formação humana em diversos aspectos. Queiroz (2009) afirma que a modelagem como estratégia didática para o ensino do tema ligação iônica contribuiu para o desenvolvimento da capacidade de visualização, que é o significado que o discente atribui a uma representação. Quando a modelagem é trabalhada em contextos adequados, segundo Maia (2009), a mesma pode contribuir para a manifestação de habilidades investigativas, como a busca por ampliar o conhecimento sobre os sistemas em estudo; a seleção de modelos prévios apropriados ao sistema em estudo; a integração de ideias, modelos prévios e informações sobre os sistemas para a elaboração de modelos tendo em vista os objetivos definidos; e analisar a extensão em que o modelo proposto atingiu seus objetivos. Mendonça (2011) destaca que a modelagem além de favorecer a melhor compreensão dos conceitos 
envolvidos pode instigar a produção de argumentos pelos discentes, uma vez que estes precisam defender seus modelos construídos. Em contextos de ensino fundamentado em modelagem o processo de co-construção, ou seja, a construção do conhecimento científico por meio de interações entre o educador e o educando ou entre educandos, também é favorecido (COSTA, 2012).

Para facilitar a utilização da modelagem como estratégia didática, os pesquisadores Rosária Justi e John Gilbert (2002), utilizando alguns aspectos da proposta inicial de Clement (1989), propõe o diagrama intitulado "Modelo de Modelagem" que foi elaborado após uma investigação das implicações na educação pelo uso de modelos e as concepções dos professores sobre a natureza da modelagem, identificaram e desenvolveram etapas inerentes ao processo de elaboração de modelos.

Na Figura 1 é mostrado o diagrama "Modelo de Modelagem" proposto por Justi e Gilbert 2002 e que utilizamos para nortear as atividades desenvolvidas nesse trabalho. A descrição detalhada desse diagrama pode ser encontrada em publicações como Gandra e Faria (2014) e Mendonça e Justi (2009) que além de descreverem todas as etapas previstas pelo diagrama, o aplicam e analisam os resultados de sua utilização que se mostram sempre eficientes.

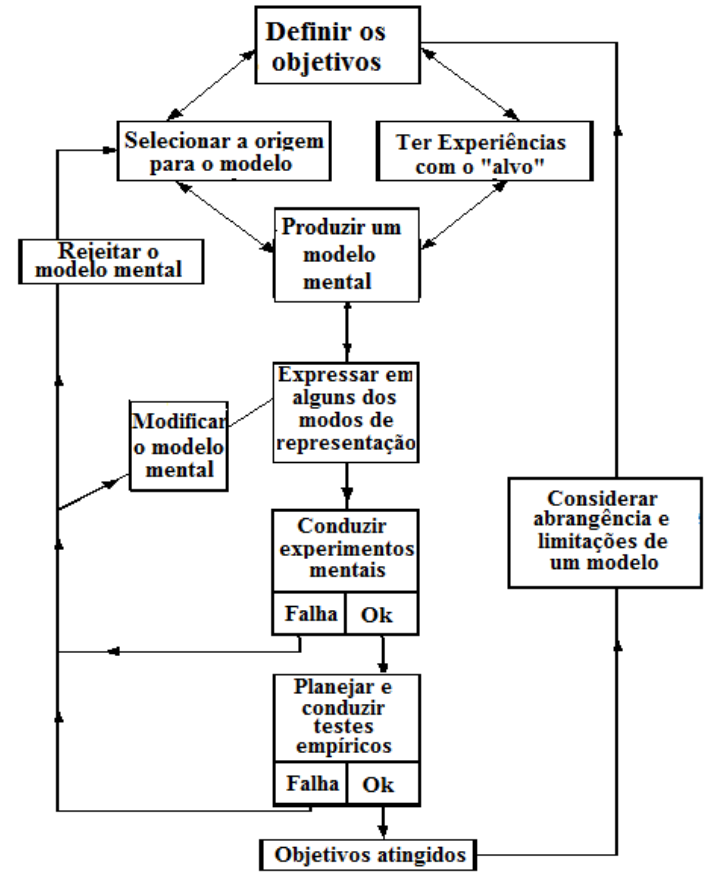

Figura 1. Diagrama ‘Modelo de Modelagem’ (JUSTI E GILBERT, 2002, p. 357).

\section{METODOLOGIA}

Ao todo participaram desta pesquisa 39 alunos do 3 Período do ensino médio integrado ao técnico em informática do IFMS câmpus Coxim. As atividades foram realizadas ao longo das aulas nas disciplinas de Química 3 e Linguagem de Programação 1 que foram desenvolvidas em diferentes etapas conforme previstas no diagrama e que a seguir são descritas.

$\mathrm{Na}$ primeira etapa realizamos um estudo aprofundado acerca dos conhecimentos gerais abordados comumente em torno dos fenômenos químicos envolvendo soluções, como molaridade, concentração comum e massa molar, satisfazendo a necessidade do estudante ter 
experiência com o fenômeno alvo conforme previsto no diagrama. A partir desse estudo, fomentamos uma discussão a respeito da abrangência e das limitações dos conteúdos supracitados, bem como a utilização destes na explicação dos fenômenos químicos que envolvem soluções, sendo que aqui definimos os objetivos iniciais para a modelagem.

Em seguida na segunda etapa foram abordados conhecimentos específicos da área profissional do técnico em informática, principalmente os enfatizados por meio da disciplina de Linguagem e Programação I, e a seleção das ferramentas necessárias para a construção de modelo computacional. Essa atividade permitiria evidenciar os conhecimentos prévios dos estudantes que seria um facilitador pedagógico.

Pautado em seus próprios conhecimentos prévios, bem como em suas experiências adquiridas nas etapas 1 e 2, propusemos a terceira etapa, na qual os discentes elaboraram seus modelos mentais para a linguagem de programação e para os códigos necessários ao desenvolvimento do modelo expresso. Nessa etapa o professor da disciplina de linguagem e programação 1 mediou a discussão até que os alunos chegassem a um modelo mental consensual conforme descrito em Gandra e Faria (2014).

A etapa 4 se caracteriza pelo desenvolvimento do modelo expresso utilizando as ferramentas estudadas na etapa 2, o que exige que os alunos adequem o modelo mental consensual ao modelo expresso que estão desenvolvendo, contemplando a expressão do modelo em alguns dos modos de representação.

Na sequência, os alunos realizaram testes a fim de verificar se o modelo contemplou os aspectos pontuados na primeira etapa, levando em consideração aí também o poder de previsão de seus modelos, bem como suas respectivas limitações.

\section{RESULTADOS E DISCUSSÕES}

$\mathrm{Na}$ primeira atividade definimos como objetivo para nossas atividades integradoras fundamentadas em modelagem representar aspectos do conteúdo de soluções químicas, visando a resolução de problemas envolvendo conceitos como concentração comum, molaridade, molalidade e diluição de soluções. A atividade 1 aconteceu durante as aulas na disciplina de química 3 na qual os alunos aprofundaram seus estudos acerca das soluções químicas, enfatizando os conceitos pontuados no objetivo. Concomitantemente a atividade 2 acontecia durante as aulas da disciplina de linguagem e programação 1 na qual os alunos estudavam as principais ferramentas da linguagem de programação em java.

Em seguida as atividades 3 e 4 aconteceram durante algumas aulas no laboratório de informática, devida a quantidade de computadores disponíveis na sala de informática que eram ao total 20 computadores, solicitamos que a as atividades integradoras fossem desenvolvidas em 18 duplas e 1 trio. E por fim a atividade 5 aconteceu durante aulas nas duas disciplinas, sendo que cada professor contribuiu para a análise dos modelos por diferentes perspectivas tanto da visão profissional quanto da visão geral. Ao partirmos para análise verificamos inicialmente que foram desenvolvidos dois modelos distintos para representerarem o conteúdo de soluções, sendo que 9 duplas optaram em desenvolver o modelo 1 com pequenas variações entre si de layout e 9 duplas e o trio optaram em desenvolver o modelo 2 também com pequenas variações de layouts entre si. 
O modelo 1 é composto por três projetos apresentando um método resolutivo para encontrar o resultado das variáveis concentração, massa e volume de maneira independente. Dessa forma o projeto 1 visa calcular apenas o valor da concentração comum, sendo que convencionou para isso que o usuário deva introduzir o número 0 na caixa de texto concentração (Figura 2), na sequência na caixa de texto 2 o usuário insere o valor da massa em gramas da solução em questão (Figura 3), e na caixa de texto 3 o usuário insere o valor em litros para o volume da solução a se calcular sua concentração comum (Figura 4). E por fim a caixa de texto 4 é de caráter informativo para apresentar ao usuário o valor da concentração da solução a que se pretende calcular (Figura 5).

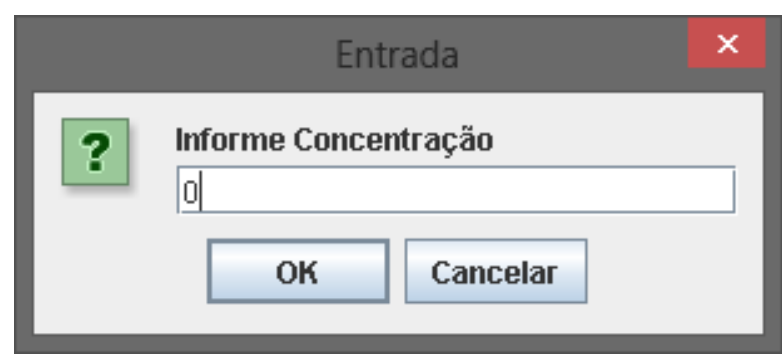

Figura 2. Interface da Caixa de Texto 1. Fonte: Autoria Própria

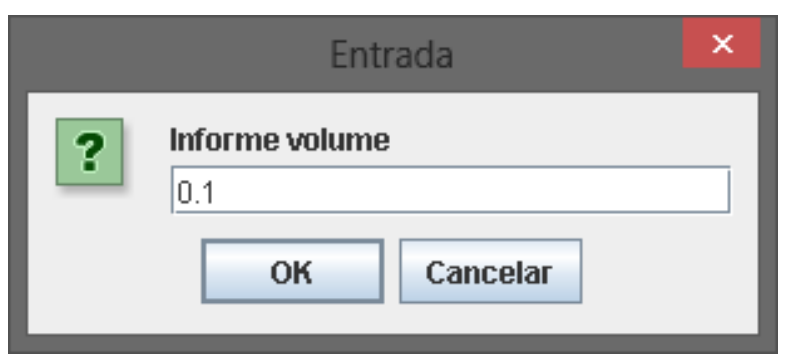

Figura 4. Interface da Caixa de Texto 3 Fonte: Autoria Própria.

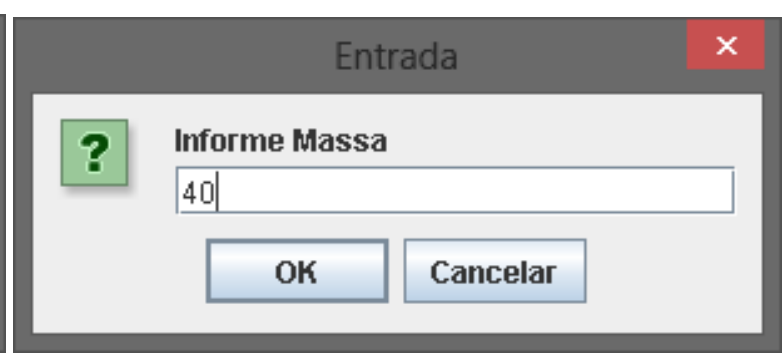

Figura 3. Interface da Caixa de Texto 2 Fonte: Autoria Própria

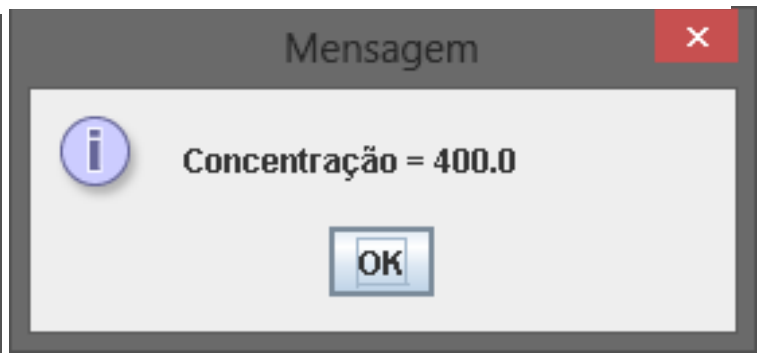

Figura 5. Interface da Caixa de Texto 4. Fonte: Autoria Própria

Na figura 6 apresentamos o código desenvolvido pelos estudantes para a execução desse primeiro projeto do modelo 1, para facilitar a compreensão por parte do leitor, adotamos o procedimento de inserir em cima de cada linha de código desenvolvida pelos discentes, comentários que elucidam a execução a qual cada linha se propõe a desenvolver. 


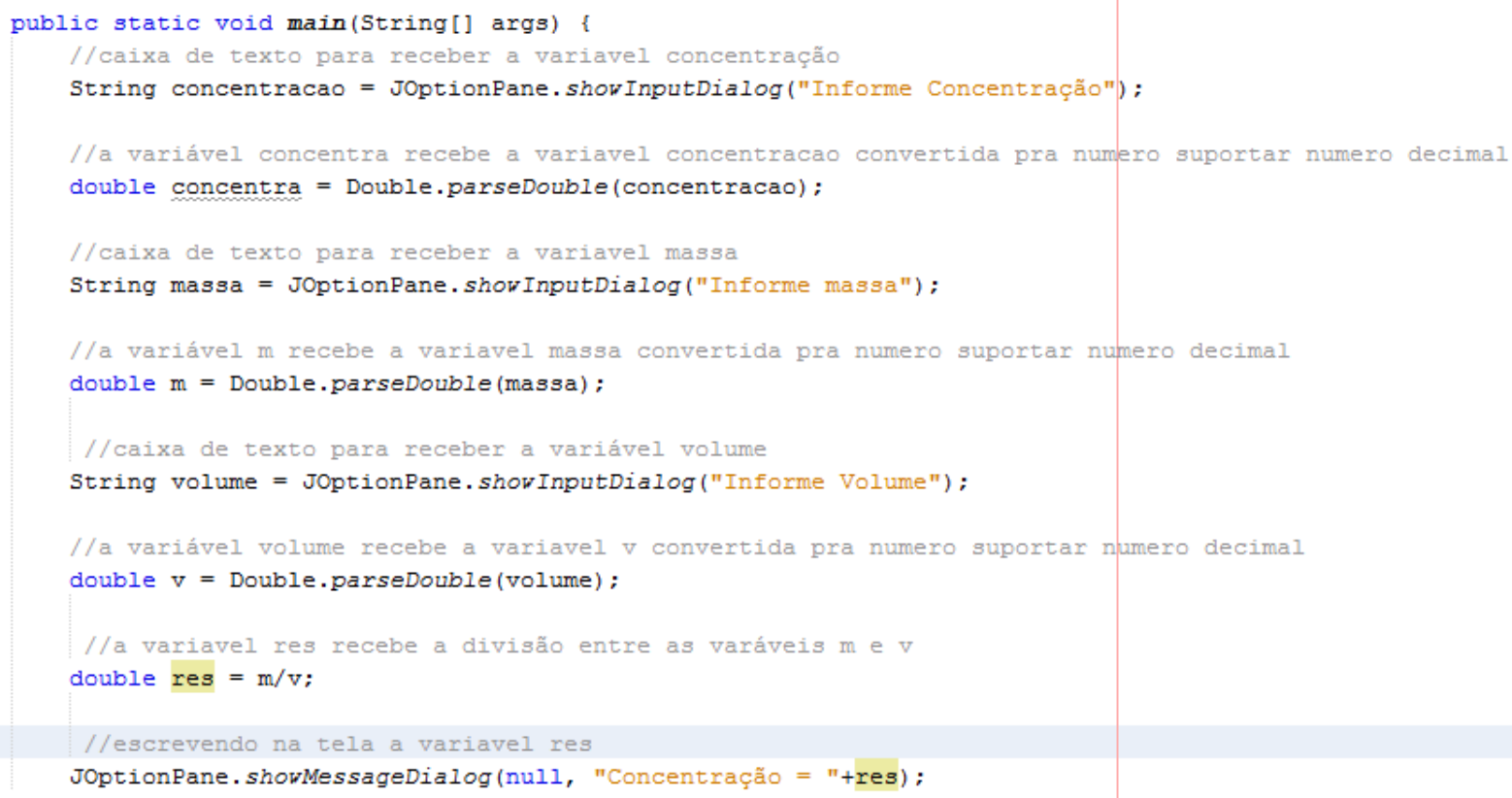

Figura 6. Código Comentado do 1 Projeto do Modelo 1 (Autoria Própria)

O segundo projeto do modelo 01, visa calcular a massa de um soluto presente em uma determinada solução, utilizando como recurso a concentração comum. Sendo assim este segundo projeto também conta com 4 caixas de texto, entretanto como se pretende calcular a massa, convencionou-se aqui que para executar tal ação, o usuário precisa informar o valor 0 na caixa de texto da massa (Figura 7), informar o valor da concentração comum em g/L na caixa de texto 2 (Figura 8), e inserir o valor do volume em em L na caixa de texto 3 (Figura 9), sendo que na caixa de texto 4 (Figura 10) o usuário receberá o valor da massa do soluto calculada pelo modelo e expressa em gramas.

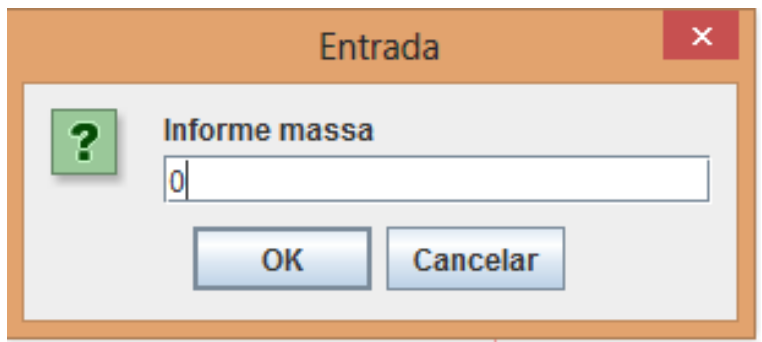

Figura 7. Interface da Caixa de Texto 1 Fonte: Autoria Própria.
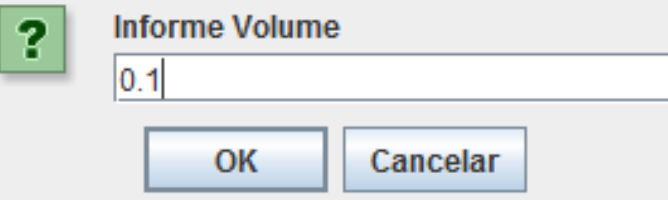

Figura 9. Interface da Caixa de Texto 3 Fonte: Autoria Própria.

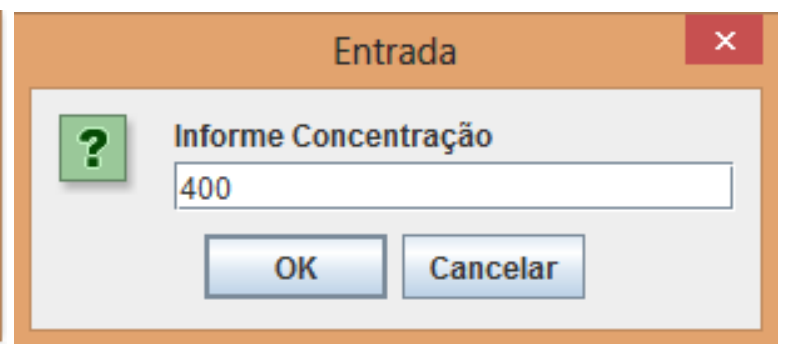

Figura 8. Interface da Caixa de Texto 2 Fonte: Autoria Própria.

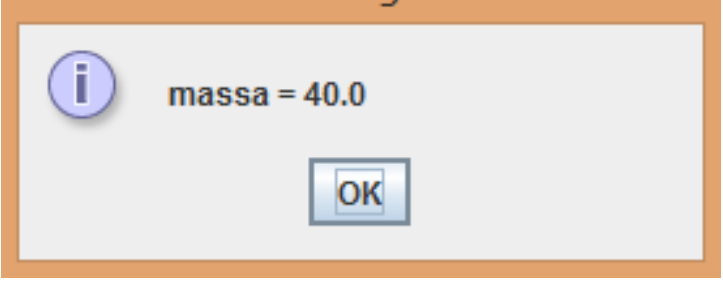

Figura 10. Interface da Caixa de Texto 3 Fonte: Autoria Própria. 
Da mesma maneira como no projeto anterior, a figura 11 traz o código desenvolvido pelos estudantes durante o segundo projeto, juntamente com nossos comentários de maneira a facilitar sua compreensão.

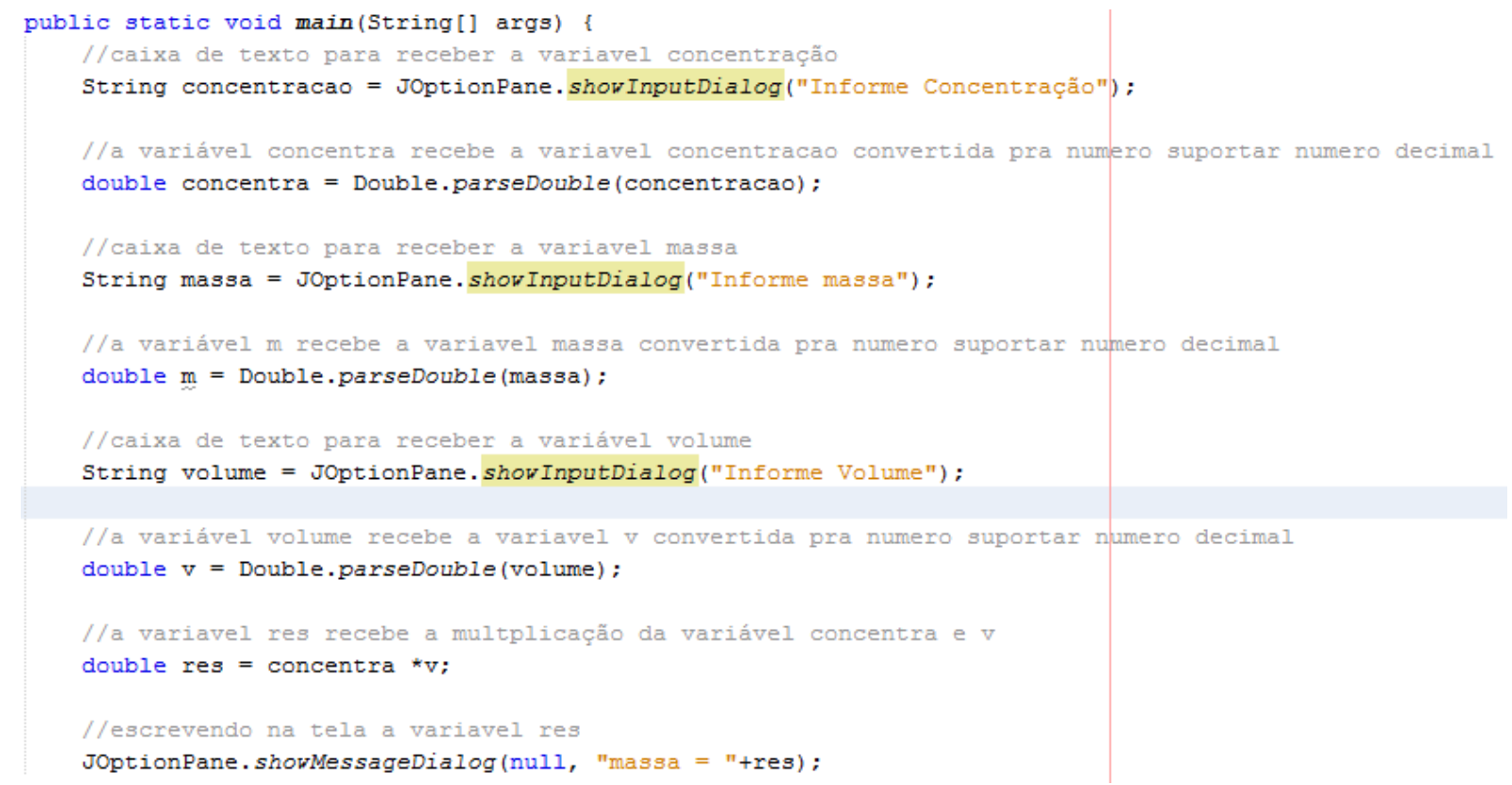

Figura 11. Código comentado do 20 Projeto do Modelo 1. Fonte: Autoria Própria

Por fim o modelo 1 traz o seu terceiro projeto visando o cálculo do volume de solvente contido em uma solução, utilizando para isso como recursos a concentração comum e a massa de soluto. Da mesma maneira que os projetos 1 e 2 , este conta com 4 caixas de textos, sendo que na caixa de texto 1 do volume (Figura 12), o usuário deve introduzir o valor 0 devido a convenção utilizada, para indicar ao modelo que aquela é a variável que se deseja calcular, em seguida na caixa de texto 2 o mesmo deve inserir o valor referente a massa do soluto em gramas (Figura 13) e na caixa de texto 3 inserir o valor da concentração comum da solução em questão expressa em g/L (Figura 14), sendo que o valor da variável do volume que se deseja calcular será informada em litros, pelo modelo na caixa de texto 4 (Figura 15).

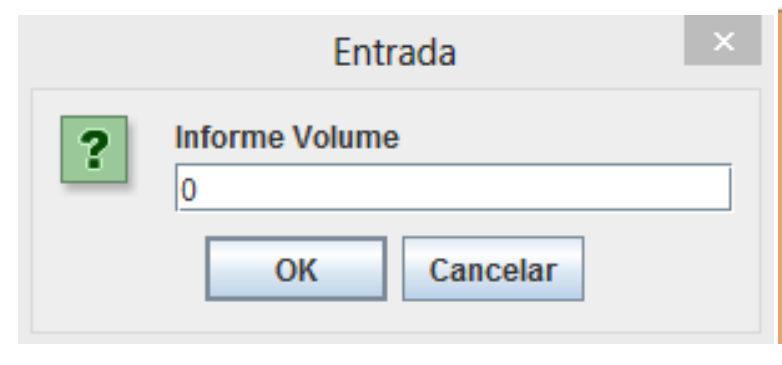

Figura 12. Interface da Caixa de Texto 1 Fonte: Autoria Própria.

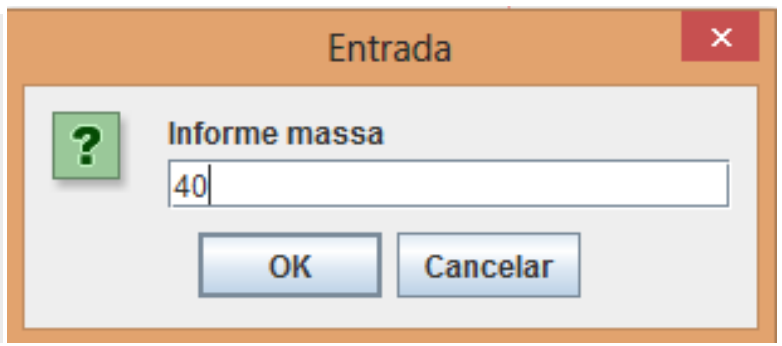

Figura 13. Interface da Caixa de Texto 2 Fonte: Autoria Própria. 


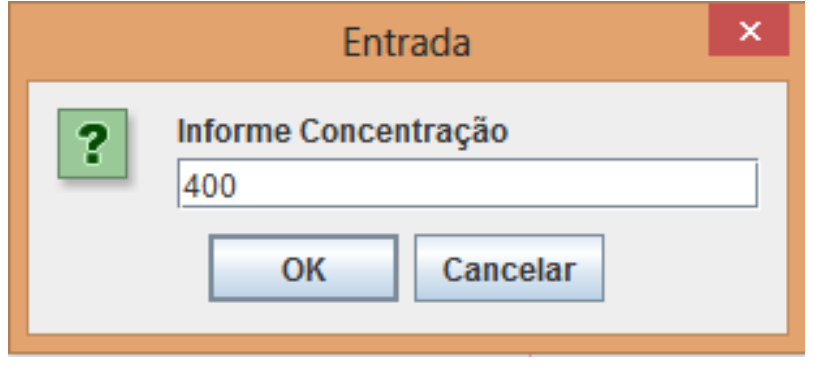

Figura 14. Interface da Caixa de Texto 3 Fonte: Autoria Própria.

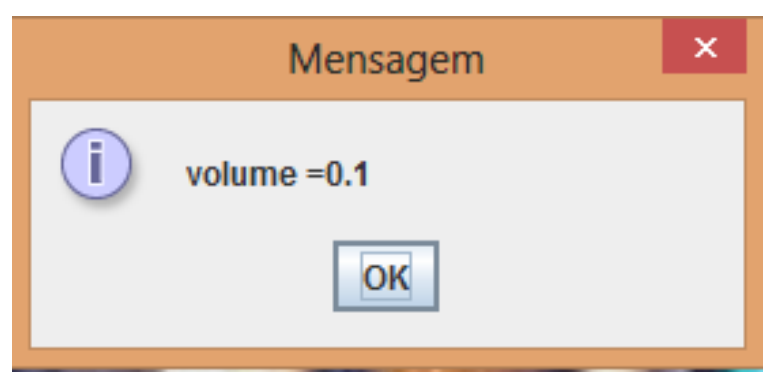

Figura 15. Interface da Caixa de Texto 4 Fonte: Autoria Própria.

Conforme também apresentamos nos projetos 1 e 2, segue também na figura 16 o código desenvolvido pelos estudantes para este terceiro projeto, e comentado por nós afim de facilitar a compreensão destes.

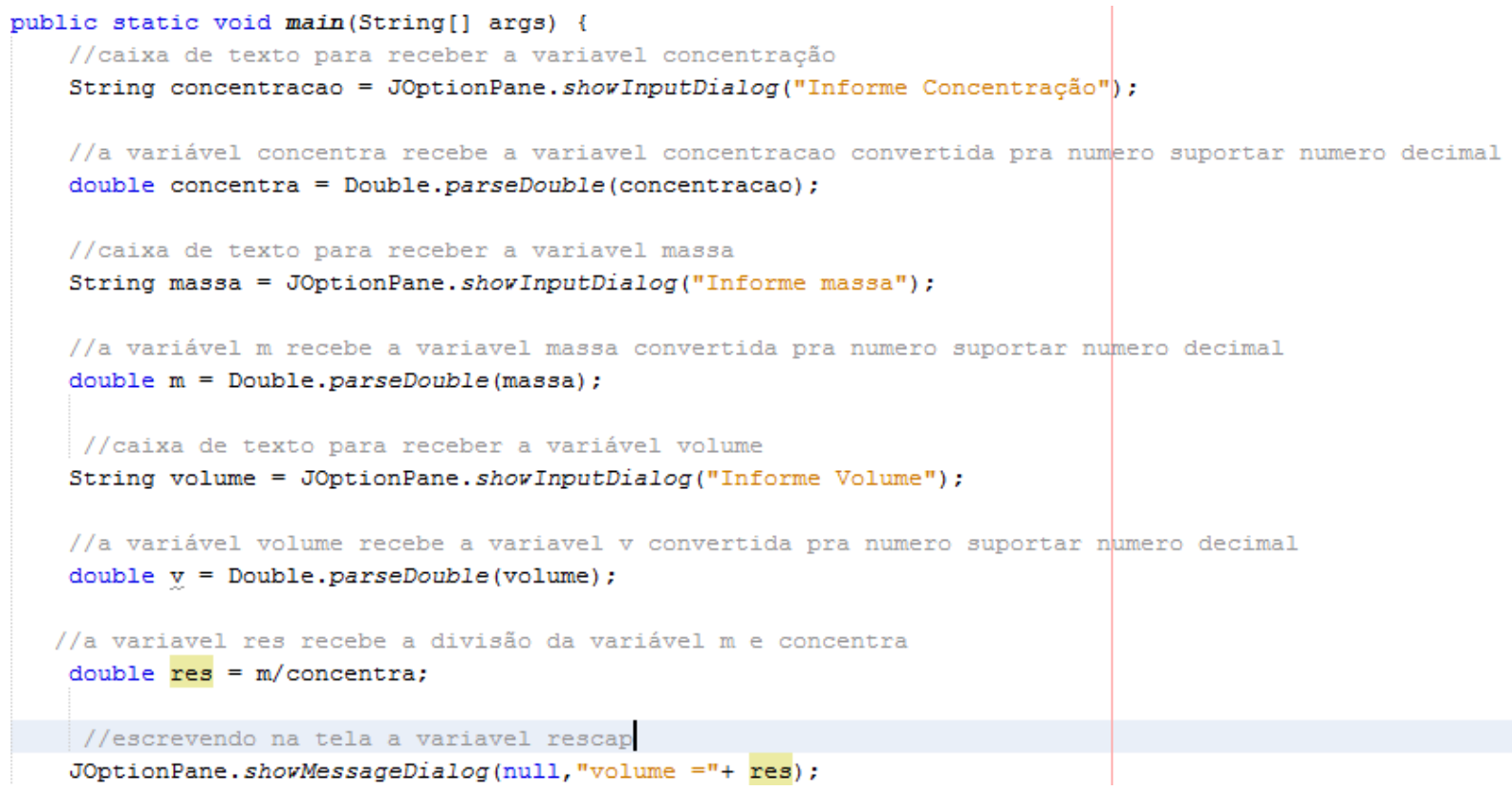

Figura 16. Código comentado do 3 Projeto do Modelo 1. Fonte: Autoria Própria

Após apresentar o modelo 1 desenvolvido pelos estudantes, cabe a nós analisá-lo considerando alguns aspectos levantandos pelo embasamento teórico oriúndo da modelagem e da concepção formativa e pedagógica do ensino médio integrado a educação profissional.

Dessa forma, primeiramente, gostaríamos de lembrar aqui que uma das etapas do diagrama "Modelo de Modelagem" (JUSTI E GILBERT, 2002) é intitulada de "considerar a abrangência e as limitações do modelo". Sendo assim, ao considerarmos o conteúdo de soluções, podemos realizar cálculos envolvendo a concentração comum, concentração molar, molalidade e ainda a diluição de soluções, o que fica perceptível uma grande limitação do modelo desenvolvido pois este prevê apenas questões pertinentes a concentração comum.

No que tange os conhecimentos específicos manifestados pelos discentes ao longo das atividades integradoras, percebe-se que os discentes que se propuseram a desenvolver o modelo 1, optaram em desenvolver um código inicial para o primeiro projeto e realizaram pequenas 
alterações nos outros dois projetos afim de contemplar em seus modelos a resolução de problemas envolvendo as três variáveis presentes no cálculo de solulções usando a concentração comum.

Enfim, um outro grupo de discentes optaram em desenvolver um outro modelo que denominamos aqui como modelo 2, caracterizado pela existência de um menu que antes de resolver qualquer problema envolvendo a concentração comum das soluções, solicita ao usuário a seleção de qual variável o mesmo pretende calcular. Tratando-se de caixas de texto o modelo 2 apresenta também 4, sendo que a primeira seria o menu (Figura 17) que apresenta números de 1 a 4 representando a opção respectivamente do usuário em calcular a concentração, a massa, o volume ou ainda sair do modelo. Para a realização de um teste, simulamos a opção em calcular a concentração comum e inserimos na primeira caixa de texto o valor 1 , dessa forma imediamente aparece as caixa de texto 2 e 3 requerendo os valores respectivamente para a massa do soluto expressa em gramas (Figura 18) e o volume de solvente expressa em litros (Figura 19), ao qual a caixa de texto 4 é apenas informativa fornecendo ao usuário o valor da váriavel calculada que em nosso teste foi a concentração comum em g/L (Figura 20).

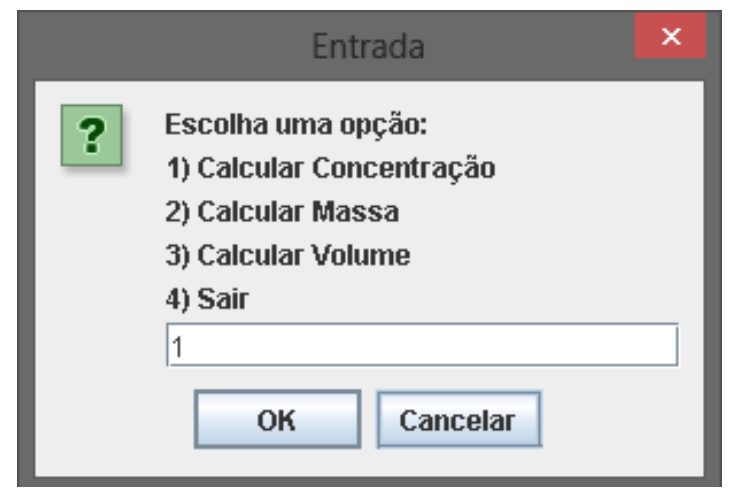

Figura 17. Interface da Caixa de Texto 1 Fonte: Autoria Própria.

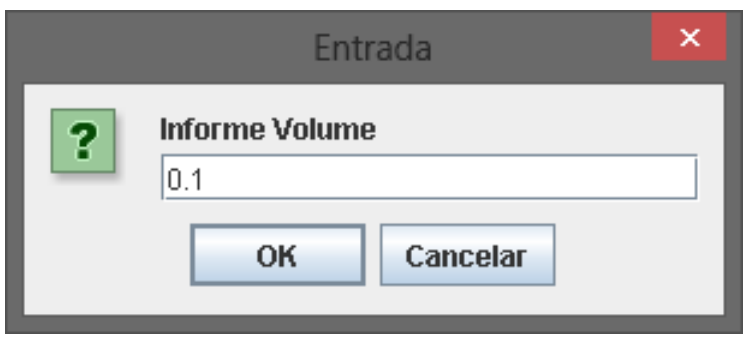

Figura 19. Interface da Caixa de Texto 3 Fonte: Autoria Própria.

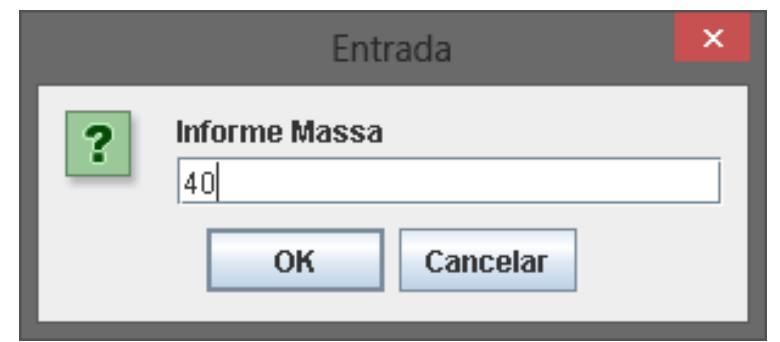

Figura 18. Interface da Caixa de Texto 2 Fonte: Autoria Própria.

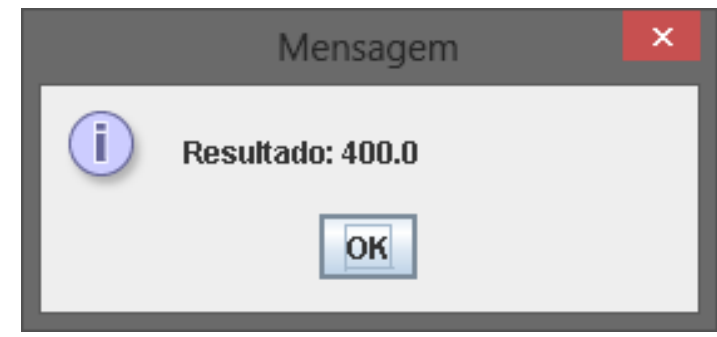

Figura 20. Interface da Caixa de Texto 4 Fonte: Autoria Própria.

Durante as atividades integradoras, os estudantes que produziram o modelo 2 desenvolveram o código mostrado na figura 21 que também acrescentamos nossos comentários antecendendo cada linha para facilitar a compreensão dos mesmos. 


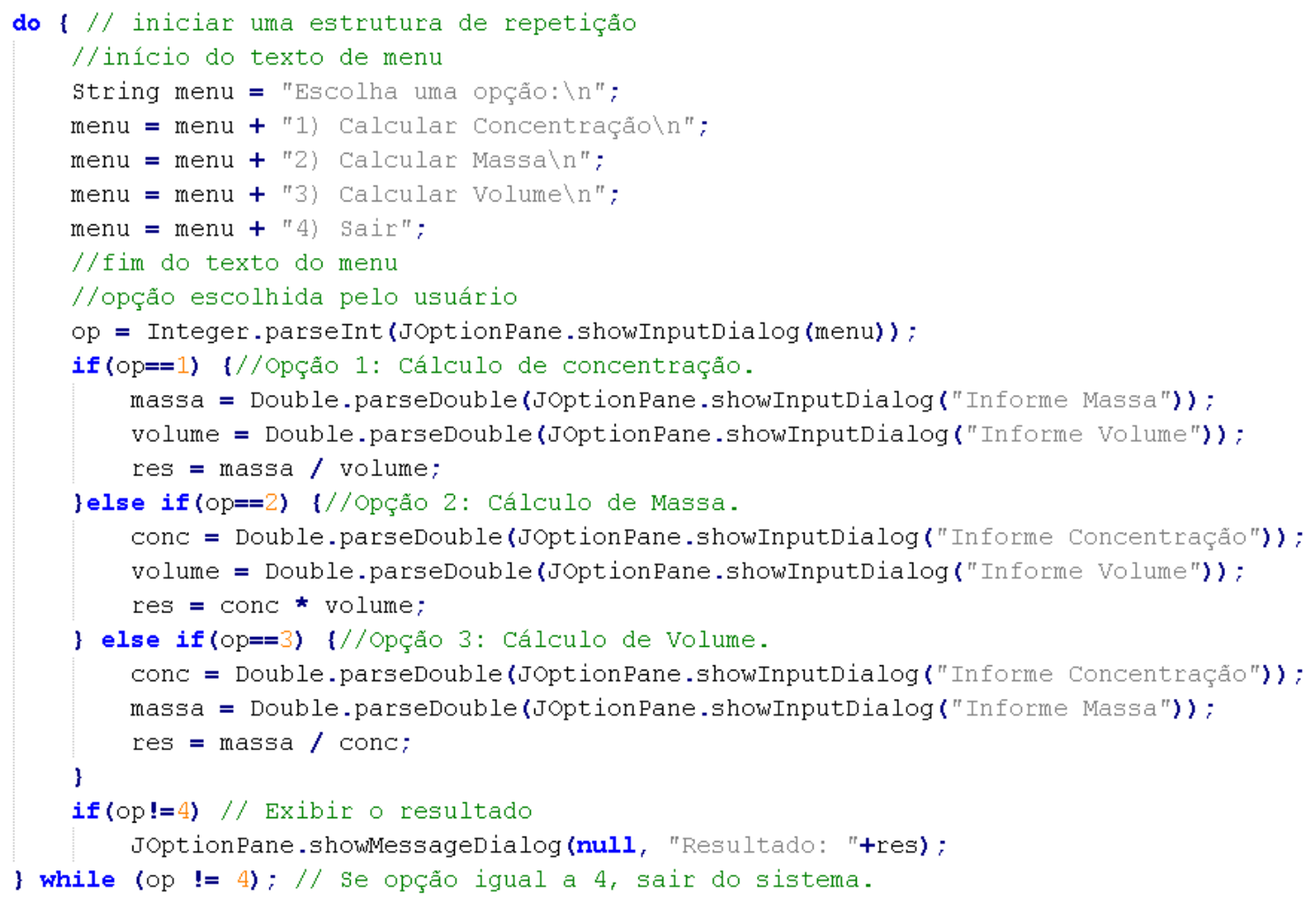

Figura 21. Código comentado do Modelo 2. Fonte: Autoria Própria

Partindo para análise do modelo 2, levamos em consideração alguns dos aspectos pontuados anteriormente, na qual este modelo atingiu o objetivo de representar parcialmente o fenômeno de soluções químicas, e cumpriu a previsão de situações envolvendo a concentração comum, entretanto também é limitada no sentido de não contemplar conceitos como concentração molar, molalidade e ainda a diluição de soluções.

Do ponto de vista profissional, foi perceptível que os alunos que desenvolveram o modelo 02, mobiliziram uma quantidade maior de conhecimentos da área profissional, pois além de se preocupar em resolver um problema geral, se preocupou também com questões profissionais visitando facilitar o máximo possível a utilização do modelo construído por diferentes usuários.

\section{CONSIDERAÇÕES FINAIS}

Ao compararmos os modelos 1 e 2, desenvolvidos durante as atividades integradoras, embora todos os alunos passaram por todas as atividades juntos, no que compete à utilização de conhecimentos da área profissional de informática, os alunos que optaram em desenvolver o modelo 2 colocaram uma maior quantidade de conhecimentos específicos em prática, demonstrando uma preocupação com os usuários e/ou cliente que utilizarão posteriormente seu modelo desenvolvido.

Já da área comum, no caso desse trabalho, a química como componente curricular, tratando em especial claro o conteúdo de soluções químicas, ambos os modelos tiveram o mesmo poder de previsão, ou seja, conseguiram prever bem os fenômenos relacionados a concenração comum das soluções, mas são limitados para calcular outros conceitos como concentração molar, molalidade e diluição. Este fato reitera a possibilidade de retornamos a primeira etapa do diagrama 
e realizarmos adaptações nos modelo aqui desenvolvidos, visando a ampliação do seu poder de previsão e/ou de representação parcial de um fenômeno, o que de certa forma é justificado, pois aqui apresentamos os resultados iniciais da nossa pesquisa neste trabalho, sendo que a continuação trata-se justamente da realização de atividades integradoras visando a adaptação dos modelos.

Entretanto, com resultados até aqui podemos responder nossa questão inicial de pesquisa, ou seja, é possível desenvolver atividades integradoras para o ensino médio integrado ao técnico em informática usando como estratégia didática a modelagem pois percebeu-se o quanto teve uma integração entre as duas disciplinas, na qual os discentes adotaram e internalizaram para si problemas envolvendo soluções químicas que era visto por eles naquele semestre na disciplina de química, e utilizaram seus conhecimentos prévios e específicos na prática afim de resolucionar esses problemas, que foi resolvido por eles de duas diferentes formas.

\section{REFERÊNCIAS}

1. ARAUjO, R. M. de L. Práticas Pedagógicas e Ensino Integrado. In: Reunião Nacional da ANPED, no 36, 2013, Goiânia, Anais da 36ạ Reunião da ANPED, Goiânia, 2013. 19p.

2. BRASIL. Documento Base da Educação Profissional Técnica de Nível Médio Integrada ao Ensino Médio. Brasília: SETEC, 2007. Disponível em:. http://portal.mec.gov.br/ setec/arquivos/pdf/documento_base.pdf Acesso em: 13 mai. 2015.

3. CIAVATTA, M. A formação integrada: a escola e o trabalho como lugares de memória e de identidade. In: RAMOS, Marise. (Org.) ; FRIGOTTO, Gaudêncio (Org.); CIAVATTA, Maria (Org.) . Ensino Médio Integrado: Concepção e Contradições. São Paulo: Cortez, 2005; pp. 83-105.

4. CLEMENT, J. Learning via Model Construction and Criticism - Protocol evidence on sources of creativity in science. In J. A. Glover, R. R. Ronning \& C. R. Reynolds (Eds.) Handbook of Creativity: assessment, theory and research. New York: Editora Plenum. 1989. p. 341-381.

5. CLEMENT, J. Model based learning as a key research area for science education. International Journal of Science Education, V. 22, n.9, p.1041-1053, 2000.

6. COSTA, P. P. Estudo do Processo de Co-construção de Conhecimento em um Contexto de Ensino Fundamentado em Modelagem. 2012. 122p. Dissertação do Mestrado em Educação - Universidade Federal de Minas Gerais, Belo Horizonte, 2012.

7. FERREIRA, P. F. M; JUSTI, R. Modelagem e o "fazer ciência". Química Nova na Escola. São Paulo, Vol. 8, n. 28, p. 32-36, maio. 2008.

8. GANDRA, L. P.; FARIA, A. G. V.; Modelo didático para a representação de estruturas que contempla as diferentes hibridizações de átomos por meio da modelagem como estratégia para o ensino de química. In: Encontro Nacional do Ensino de Química, 17., 2014, Ouro Preto. Anais...Ouro Preto, 2014. 12p.

9. GANDRA, L. P.; FIGUEIREDO, C. V. da S.; Levantamento bibliográfico acerca do ensino médio integrado à EPCT: breves reflexões sobre as orientações disponíveis no sítio da SETEC. In: Encontro de Iniciação Científica do IFMS, 3., 2013, Nova Andradina. Anais...Nova Andradina 2013. 10p.

10. GILBERT, J. K; BOULTER, C. J.; ELMER, R. Positioning models in science education and in design and technology education. In J. K. GILBERT; C. J. BOULTER (Org.). Developing Models in Science Education. Dordrecht: Editora Springer, 2000. p. 3-18. 
11. JUSTI, R.; GILBERT, J. K. Modelling, teacher's views on the nature of modelling, implications for the education of modelers. International Journal of Science Education. Vol 24, n.4, p.369-387, 2002.

12. MAIA, P. F. Habilidades investigativas no ensino fundamentado em modelagem. 2009. 239p. Tese do Doutorado em Educação - Universidade Federal de Minas Gerais, Belo Horizonte. 2009.

13. MENDONÇA, P. C. C. 'Ligando' as ideias dos alunos à ciência escolar: Análise do ensino de ligação iônica por modelagem. 2008. 241p. Dissertação do Mestrado em Educação Universidade Federal de Minas Gerais. Belo Horizonte,2008.

14. MENDONÇA, P. C. C. Influência de atividades de modelagem da qualidade dos argumentos de estudantes de química no ensino médio. 2011. 282p.Tese do Doutorado em Educação - Universidade Federal de Minas Gerais, Belo Horizonte, 2011.

15. MENDONÇA, P. C. C; JUSTI, R. Favorecendo o aprendizado do modelo eletrostático: análise de um processo de ensino de ligação iônica fundamentado em modelagem. Parte I. Educación Química. 2009; 20:282-94. (Extraord.)

16. NERSESSIAN, N. J. Model-Based Reasoning in Conceptual Change. In: International Conference Model-Based Reasoning in Scientific Discovery, 11, Pavia Italia, Anais... Pavia Italia: MBR, 1998.p. 5-22. 1998.

17. QUEIROZ, A. S. Contribuições do Ensino de Ligação lônica Baseado em Modelagem ao Desenvolvimento da Capacidade de Visualização. 2009. 258p. Dissertação do Mestrado em Educação - Universidade Federal de Minas Gerais, Belo Horizonte, 2009.

18. RAMOS, M. N.; Concepção de Ensino Médio Integrado. 2008. Disponível em: http://www.iiep.org.br/curriculo_integrado.pdf. Acesso em: 15 mai. 2015. 